\title{
THE EFFECT OF FRACTIONATED DOSES OF ELECTRONS AND PROTONS ON HAIR FOLLICLES IN THE ALBINO RAT
}

\author{
Masters Thesis
}

Paul T. Strickland

\author{
New York University \\ New York, N. Y.
}

April 30, 1974

\section{PREPARED FOR THE U. S. ATOMIC ENERGY COMMISSION UNDER CONTRACT NO. AT (11-1) 3380}

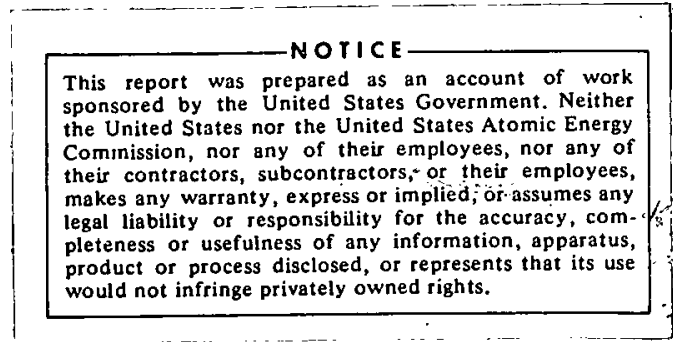




\section{DISCLAIMER}

This report was prepared as an account of work sponsored by an agency of the United States Government. Neither the United States Government nor any agency Thereof, nor any of their employees, makes any warranty, express or implied, or assumes any legal liability or responsibility for the accuracy, completeness, or usefulness of any information, apparatus, product, or process disclosed, or represents that its use would not infringe privately owned rights. Reference herein to any specific commercial product, process, or service by trade name, trademark, manufacturer, or otherwise does not necessarily constitute or imply its endorsement, recommendation, or favoring by the United States Government or any agency thereof. The views and opinions of authors expressed herein do not necessarily state or reflect those of the United States Government or any agency thereof. 


\section{DISCLAIMER}

Portions of this document may be illegible in electronic image products. Images are produced from the best available original document. 


\section{ABSTRACT}

A study of the effect of single and fractionated doses of electrons and protons on Albino rat hair follicles has been undertaken. The survival and regrowth curves of hair follicles following irradiation are presented. Temporary hair suppression was evident from the delay in regrowth of new hair, which was about one day of delay per 100 rads for protons. It was found that permanent growth suppression occurred at 4800 rads for electrons and at a dose greater than 1200 rads for protons. The doses required to produce $50 \%$ follicle suppression at ten days post irradiation were 700 rads and 2100 rads for protons and electrons, respectively. A fractionation effect was found for both types of radiation with about $60 \%$ recovery for protons and $100 \%$ recovery for electrons. 


\title{
TABLE OF CONTENTS
}

\begin{abstract}
TABLE OF CONTENTS

ACKNOWLEDGMENTS
\end{abstract}

Page

\section{Chapter}

I. INTRODUCTION

A. Objective $\quad \ldots \quad 1$

B. The Hair Follicle $\quad \therefore \quad 1$

C. Fractionation of the Radiation 3

D. Stem Cell population of the Follicles 4

II. MATERIALS AND METHODS 7

A. Experimental Animals 7

B. Proton Beam and Irradiation System 7

C. Electron Beam and Irradiation System 9

D. New Hair Growth Observation 10

1) Photographic Method 10

2) Follicle Elongation Method 11

III. RESULTS $\quad \cdots \quad: \quad \cdots \quad 13$

A. Protocol $\quad \therefore \quad \ldots . \quad 13$ 
Page

B: Protons $\quad: \quad \ldots \quad 14$

1) New Hair Growth $\quad \cdots \quad 14$

2) Follicle Elongation 15

3) Fractionation Effect for Follicles 15

C. Electrons 16

1) Follicle Elongation 16

- 2) Fractionation Effect for Follicles 16

D. Stem Cell population 19

IV. DISCUSSION 21

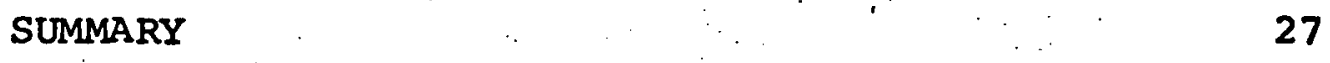

REFERENCES $\quad 28$

FIGURES

APPENDIX I: Electron Dosimetry : : 47

APPENDIX II: Proton Dosimetry $\quad \cdots 48$

APPENDIX III: Biopsy Staining Procedure 51 


\section{ACIONOWLEDGMENTS}

This work was performed at the Inst1tute of Environmental Medicine in the radiological health training program administered in cooperation with the Department of Civil Engineering.

I. would Iike to thank Dr. Fredric Burns who suggested the initial experiments, for his continued assistance and advice. I would also like to thank Martin Vanderlaan and Nrs. Betty Skocik ror assisting in the experiments and the histological procedures: I am grateful to Dr. Tom Kuo at Sloan-Kettering for helping with the proton dosimetry and cyclotron adaption.

I would like to thank Francis Standish for helping with the experimental animals and express my appreciation to Mrs. Elsie Bilger for tiping this thesis. 


\section{CHAPTER I}

INTRODUCTION

\section{Objective}

It has been suggested by several studies undertaken in this laboratory ${ }^{1,2,3}$ that the stem cells at the tips of the hair follicles are the critical skin components for the production of abnormal follicles and tumors by radiation. The purpose of this study is to obtain a more complete understanding of how the hair follicle cells recover from the effects of diverse types of radiation. The specific objective is to obtain hair follicle survival and regrowth curves in rat skin following irradiation with various single and fractionated doses of protons and electrons.

\section{The Hair Follicle}

Hair suppression is an important index of the biological effect of radiation on mammalian skin. Hair follicle development and the cjclic growth of hair in the rat have been studied extensively $4,5,6$. An in depth study of the radiosensitivity of the hair of the Albino rat to $x$-rays was performed by Geary? It was found that radiosensitivity was very dependent on the hair cjcle phase at the time of irradiation. 
Maximum sensitivity occurred during the active phase (days 12-15), and minimum sensitivity occurred during the resting phase (days 25-28). Regrowth of hair subsequent to epilation was found to be more complete when the exposure occurred during the resting phase. The median effective dose of $x$-rays capable of producing complete epilation in 50\% of the animals exposed was 1740 rads during the resting phase.

A procedure employed by Burlin, et $a l^{8}$ in mice, involves plucking the hair in confunction with irrediation. The extent of the damage to the hair follicles is exhibited either by 1) a delay in the regrowth of hair or 2) by the absence of regrowth.

It was found that the delay in regrowth (temporary damage) and the absence of regrowth (long-term damage) both increased with increasing exposures of $x$-rays over the range 500 to 5000 rads. A different and more enlightening indicator of damage to the hair follicle cells is the delay or absence of follicle elongation and enlargement prior to hair regrowth. Whether a delay in hair regrowth is caused by a slowing down of coll proliferation associated with follicle elongation or merely by a delay in initiation of the process would not be apparent if external hair protrusion were 
the only indicator.

Practionation of the Radiation

The fractionation effect has been documented

for a variety of biological end points, including induction of ulceration and tumors in rat skin. Also hair suppression following $x$-irradiation in tho mouse has been investigated by Burlin, et al9. It was found that the length of time between fractions was a significant factor in hair regrowth: The magnitude of the second dose, needed to produce the same degree of hair suppression as a single dose, increases with the length of the time interval between doses. The size of the second dose is indicative of the degree of recovery exhibited by the follicles. A maximum recovery occurred at a dose interval of four days and recovery at 24 hours was about $40 \%$.

Recovery with respect to atrophic follicle induction in rats has been investigated by Burns, et al ${ }^{10}$. The difference $\left(D_{2}-D_{1}\right)$ between the fractionated dose $D_{2}$ of electrons and the single dose $D_{1}$ for equal effects was studied. With an Initial dose of 750 rads and a time interval of 31 days, 
$\left(D_{2}-D_{1}\right)$ was found to be 600 rads for incidence of atrophic follicles at 80 weeks, which is equivalent to $80 \%$ recovery. A similar result was obtained for a time interval of 24 hours (unpublished data). Recovery of mammalian cells from radiation is generally divided into two components ${ }^{11,12}$.

1) Intracellular (Elkind) recovery from sublethal injury which is complete in less than 24 hours.

2) Repopulation of cells by proliferation of the stem cell population retaining reproductive integrity. Repopulation time depends on cell cycle time and proportion of dividing and differentiating cells in the population but generaliy requires days or weoks for completion.

Intracellular recovery from sublethal injury. occurring within 24 hours has been shown to decrease with increasing LET (Iinear energy transfer) of the radiation according to Fowler ${ }^{13}$. Thus a higher IET particle would be expected to exhibit a less prominent shoulder and consequently a smaller fractionation effect.

Stem Cell Population of the Follicles

The ability of the hair follicle to survive irradiation depends on the survival of the stem cell 
population of the hair germ. According to Geary ${ }^{7}$ temporary epilation is caused by damage to the epidermal elements of the follicle which anchor the hair shaft to the follicle base. Whereas permenent epilation is caused by killing or inactivation of the cells of the hair germ. Higher doses of radiation are required for permanent epilation than for temporary epilation because of repopulation of the stem cell population.

Byं assuming multicell follicle inactivation, and at the same time single target cell inactivation, an estimate of the number of germ cells can be made from the survival curve data ${ }^{12}$. The survival curve of the follicles would then be identical in form to that encountered in multi target survival theory ${ }^{14}$ :

$$
S=1-\left(1-e^{-k D}\right)^{n}
$$

where. $n=\#$ of targets (stem cells) per follicle $\mathrm{D}=$ dose $k=$ sensitivity constant That is, each germ cell is equivalent to a single target and the entire follicle acts as a mult targot system. The above equation simplifies to:

$$
S=n e^{-k D}
$$

for large D. Thus in a semilogarithmic presentation 
of the survival curve, $n$ is synonymous with the extrapolation number, and a rough estimate of the size of the stem cell population can be inferred.

\&: 


\section{CHAPTER II}

\section{MATERIALS AITD METHODS}

Experimental Animals

Male Albino CD strain rats from the Charles River Breeding Farms, Brookline, Massachusetts were the experimental animals in this experiment. The rats were delivered at 21 days of age and irradiated at. 28 days, in the middle of the first hair resting phase ${ }^{7}$. The rats.were shaved the day before irradiation to insure uniform penetration of the skin; and the hafr in the irradiated skin was plucked following irradiation by means of a depilatory wax in order to initiate a now hair growth cycle simultaneously in all rats. Two rats out of 67 in the proton experiment and none of the 72 rats in the electron experiment exribited premature hair growth, indi ating an advanced hair cycle; and were removed from the experiment. Before irradiation the rats were anesthetized by intraperitoneal infection of Nembutal (25 mg/kg) to insure absence of movement. Following irradiation the animals were housed two per cage and provided with food and water ad libitum.

Proton Beam and Irradiation System

The proton beam used in this experiment was 
produced by the $15 \mathrm{MeV}$ cyclotron at Sloan-Kettering Institute for Cancer Research in New York City. The cyclotron ras capable of producing a beam of $10 \mathrm{MOV}$ protons of strength $2.2 \times 10^{8}$ protons $/ \mathrm{cm}^{2}$ sec, which was equivalent to a beam current of 0.4 nanoamps. The final dose rate to the animals was $138 \mathrm{rad} / \mathrm{m}$. (For detailed dosimetry, see Appendix II). The beam was diffused and degraded in the beam tube by means of aluminum foils to obtain uniformity of beam spread and the desired energy characteristics (Figure 3).

The beam was monitored with an argon filled double ionization chamber which was calibrated by means of a removable beam stop (Faraday cup) in the beam tube. A 1.0 gap parallel plate ionization chamber was also used to determine depth-dose characterigtics (see Appendix II).

Because the depth-dose curve for protons is the familiar Bragg curve and a linear depth-dose curve was desired, the energy characteristics of the beam were modified. A spinning disc absorber wheel was used which produced the necessary linear depth-dose by means of differential absorption in aluminum folls of various thicknesses. By superimposing different segments of the Bragg curve, one can adjust the 
depth-dose curve, by means of the beam modifier, to any shape needed, (Figure 1). A beam reduction factor of $10 \%$ is introduced here because of the ribs in the spinning disc.

The depth-dose curves were determined by placing various thicknesses of aluminum absorber foils between the beam and ionization chamber. These curves and the beam spread were confirmed by exposing stacks of Kodak Translite film in the beam.

The rats were irradiated in small wooden boxes. The box lids were $1 / 4$ inch plywood with an irradiation window $2 \times 5 \mathrm{~cm}$. The boxes were padded with foam to press the back of each rat against the window. In order to irradiate several rats per exposure, twelve rats were fastened to the rim of a revolving turntable, $94 \mathrm{~cm}$ in diameter, which rotated through the beam 18 times per minute. This exposes each animal to the beam $1 / 115$ of the total exposure time.

Electron Beam and Irradiation System

A $1.00 \mathrm{MeV}$ Van de Graaff accelerator located at the Union Carbide Research Laboratory in Tuxedo, New York was used to produce the electron beam used in this experiment. The beam scattered through $130 \mathrm{~cm}$ 
of air and was partially absorbed by a $0.6 \mathrm{~cm}$ Lucito sheet containing a $0.6 \mathrm{~cm}$ hole, centered on the beam, in order to reduce beam strength. The energy of the electrons was $0.7 \mathrm{MeV}$ and the initial beam current 220 uamps, jielding a dose rate of $460 \pm 46 \mathrm{rads} / \mathrm{min}$ 'at the site of exposure. (See Appendix I for dosimetry calculations). The 1.0 gap parallel plate ionization chamber was used to determine dose rates and the depth-dose distribution, (Figure 2). This curive was confirmed by exposing Kodak Transilte film stacks to the beam.

Because of the large beam spread several animals could be exposed simultaneously. An irradiation board was constructed which could hold 21 rats in three parallel rows, thereby simplifying the exposure considerably. A $2 \times 5 \mathrm{~cm}$ window formed the exposure area on the backs of the rats. The boxes were constructed of cardboard with a $1 / 16$ inch metal she日t covering the face of the system, with openings corresponding to the exposure windows.

New Hair Growth Observation

1) Photographic Mothod

In order to record the growth of new hair 
subsequent to irradiation and plucking, the back of each rat was photographed at one week intervals up to four weoks after exposure at which time the growth cycle was completed. The rats were anesthetized with ether and photographs were taken through a microscope magnifying the skin 16 times. A high intensity dissecting lamp was used. for illumination and Kodak Plus X Black and White Pan Film (ASA 125) - was used in exposures of 0.5 sec. After development of the film, slides were made and the total number of hairs visible per unit area $\left(0.09 \mathrm{~cm}^{2}\right)$ of skin was recorded for each rat. This method counts a regrown hair as any hair which protmudes through the epidermis and is visible on the surface.

2) Follicle Elongation Method

Prior to hair erupti: n, the follicle germ cells proliferate and the follicle elongates and enlarges ${ }^{6}$. This elongation can be observed and quantitated histologically, thus indicating what proportion of follicles have been inhibited from undergoing cell multiplication. Biopsies of skin were taken at one week intervals up to four weoks after irradiation and plucking. The biopsies were 
then stained with Shiff's reagent, and cleared with a procedure involving alcohol, xylene, and methyl salicylate. (See Appendix III for details).

Elongated follicles were counted under microscope magnification of $80 \mathrm{x}$. Only those follicles which were protruding through the collagen layer and exhibiting an obviously enlarged root bulb were counted. Total numbers of elongated follicles were recorded per unit area of field $\left(0.07 \mathrm{~cm}^{2}\right)$. 


\section{CHAPTER III}

\section{RESULTS}

Protocol

The doses administered and the size of the individual dose groups are shown in Table I.: The last four groups in each experiment received fractionated doses with a twenty-four hour time interval. The proton doses were intended to be twice as large as those indicated in Table I, however technical problems involving dosimetry were encountered (see Appendix II).

\section{TABLE I}

Protons (Exp.91)

$\frac{\text { Dose (rads) }}{0 .(00 \text { trols) }}$

0 (controls)

75

150

300

450

600

750

1250

$150+150$

$150+300$

$150+450$

$150+600$ $\frac{\# \text { rats }}{6}$

6

5

6.

6

5

6

6 .

4

5

6.

$\frac{6}{67}$
Electrons (Exp.98)

Dose (rads) \# rats

0 (controls)

6

600

6

1200

2400

12

3600

6

4800

6

6000

$1200+1200$

$1200+2400$

6

$1200+3600$

6

$1200+4800$

$\frac{6}{72}$ 


\section{Protons}

1) Now Hair Growth

One of the methods used to quantitate hair growth involved photographing the irradiated areas at wookly intervals. The total number of hairs visible per unit area $\left(0.09 \mathrm{~cm}^{2}\right)$ is shown aș a function of post irradiation time in Figure 4 for the proton experiment. The spread of the points at day ten and the subsequent - grouping at daj 17 Indicates a delay of hair regrowth - rather than long-term damage at these low doses. In Figure 5 the number of new hairs is plotted against time in order to. show the kinetics of delay. The new hair appearance rate per unit area was calculated from the data in Figure 4 by subtracting the total hair count of the previous week from that of the week being calculated; in this way only the new hair erupting in. the previous seven days is counted. It can be seen from this figure that as the dose increased, the periods of maximum new hair growth were delajed, with the largest delay in the 1250 rad group. Figure 3 shows the time to reach $50 \%$ normal hair density as a function of dose. The slope of the straight inge through the points is about one day of delay per 100 rads of protons. The ten day total hals counts 
(from Figure 4) are plotted as a function of dose in Figure 6, with error bars of plus or minus one standard error. The inhibition of growth is $50 \%$ at about 450 rads for the ten dey time point.

\section{2) Follicle Elongation}

The elongation of follicles was quantitated in the proton experiment at weekly intervals up to ono month. The ten day point again indicates temporary delay as shown in Figure 7, where the total number of growing follicles per unit area $\left(0.07 \mathrm{~cm}^{2}\right)$ is plotted as a function of dose. Temporary follicle growth inhibition was about 50,0 at 750 rads. The same data is plotted on semilogarithmic graph paper in Figure 8. The curve declines exponentially above 450 rads and exhibits an extrapolation number of 3.2 at ten days. Er:or bars are plus or minus one standard error.

3) Fractionation Effect for Follicles

A fractionation effect appears in the proton experiment data for temporary follicle suppression (Figure 8). The fractionated doses at 600 and 750 rads show slightly increased follicle counts suggesting that some recovery did occur between the initial 250 rad dose and the second doses. This difference 
of 43 follicles at 600 rads is significant at a confidence level of $81 \%$. The corresponding difference at 750 rads is significant at a confidence leveI of $87 \%$.

Electrons

1) Follicle Elongation

The elongation of follicles was quantitated in the electron experiment at weekly intervals up to one month as in the proton experiment. The ten and twenty-four day post-irradiation graphs are shown in Figures 9 and 10 respectively, for follicle elongation after electron exposures. The ten day point exhibits temporary inhibition of $50 \%$ at about 2100 rads; whereas the 24 day point, which is indicatire of long-term damage, reaches 50\% inhibition at 3000 rads. The same data is plotted on a semilogarithmic scale in Figures 11 and 12. The shoulder of the curve appears to broaden with time (comparing Figures II and 12), showing some recovery over the two weok interval between the two biopsies: Both graphs exhibit a sigmoid survival curve which has been observed previously ${ }^{2}$ for halr follicles.

2) Fractionation Effect for Follicles

The fractionation effect for electrons on 
follicle elongation is evident at both 10 and 24 day points. At the ten day point (Figure 9) the shift between the effect of practionated end single electron doses is significant at the $67 \%$ confidence level in the 2400 rad dose group. At 3600 rads the difference is more obvious and significant at the $99.9 \%$ confidence level.

The 24 day data for electrons (Figure 10) again shows fractionation shifts in the 2400 and $3600 \mathrm{rad}$ dose groups. The confidence levels of these differences are $98 \%$ at 2400 rads and $76 \%$ at 3600 rads. The 24 day post-irradiation point indicates long-term follicle suppression as compared to temporary suppression at 10 days. The differences between single and fractionated follicle counts and the corresponding significance levels of these shifts are sumarized in Table II. 


\section{TABLE II}

FRACTIONATION EFFECT

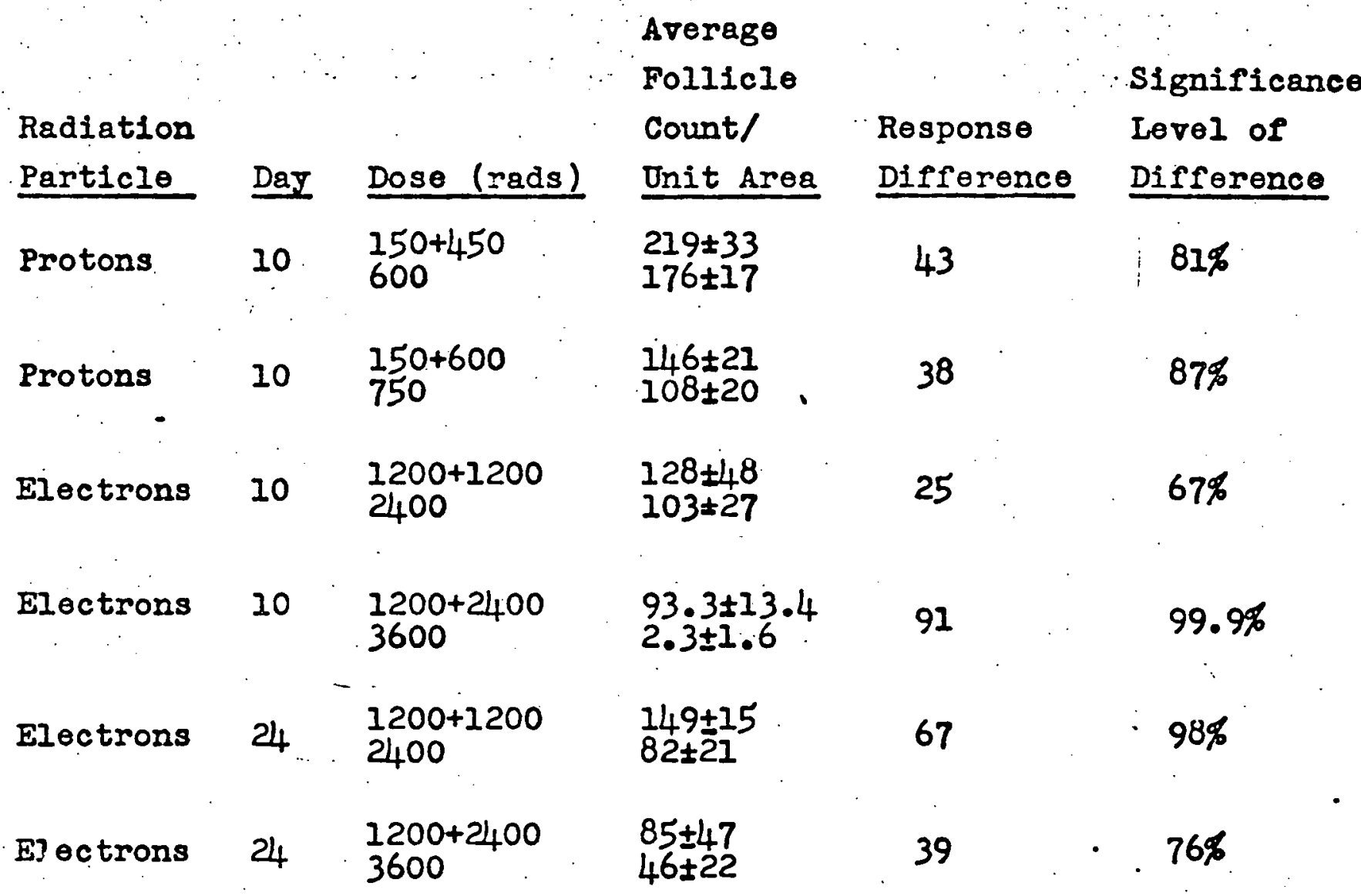

Note: Day 10 = temporary suppression Day $24=$ long-term suppression 
Stem Cell Population

The stem cell population of the resting halr follicle can theoretically be estimated from the extrapolation number of the permanent hair suppression curve. Because the doses administered in the proton experiment were lower than the 50\% suppression dose, the regrowth of hair at 27 days was complete and the hair survival curve did not deciine exponentially as expected (Figure 13). For this reason the proton experiment did not jield an estimate of the extrapolation number.

The electron data (Figures 11 and 12) is more informative than the proton data. An extrapolation number at 10 days (Figure 12) would vary considerably depending on how the extrapolation line is drawn. A maximum of about 1000 is obtained for the extrapolation. number when the 3600 rad dose point is assumed to be the most reliable high dose point. A more conservative estimate of 100 results from the use of the 4800 rad dose point in the extrapolation line.

The long-term suppression of hair is exhibited in Figure 11, which is at 24 days post irradiation. The 6000 rad dose point has been rejected because the apparent increase in growing follicle count did 
not result from hair regrowth within the irradiated area, but from the movement of adjacent hair and tissue into the irradiated area caused by contraction of the radiation scar. If the 4800 rad dose group is used, an extrapolation number of well over 10,000 is found. 


\section{CHAPTER IV}

\section{DISCOSSION}

Both long-term and temporary hair suppression are evident in the regrowth curves. Long-term suppression is demonstrated in Figure 10 (day 24) for electrons, where the mean follicle count declines to $50 \%$ at about 2700 rads. This value is higher than Geary's estimate of 1740 rads for complete epilation in $50 \%$ of the animals following $x$-irradiation. A plateau region 1200 rads wide is also evident.

By comparison between Figures 9 and 10, it can be seen from the slopes of the two curves that somo of the suppression at the ten day point was temporary. At the 24 day time point (Figure 10) the slope of the churve has declined considerably and the 50\% suppression dose increased from 2100 to 2700 rads. Burlin 8 has found that $50 \%$ hair suppression in mice results from a $2000 \mathrm{rad}$ dose of $x$-rays. Assuming that electrons and $x$-rays have the same relative biological effectiveness (RBE), it appears that rats are $35 \%$ moro resistant to radiation induced hair suppression. Whether this difference in resistence to radiation is due to a penetration effect or difference in folliclo 
resistance is not known.

Long-term and temporary hair suppression resulting from proton irradiation can also be compared using Figures 8 and 13. At the ten day point, 50\% hair suppression occurs at 700 rads. However at 24 days regrowth is complete at ell doses up to and including 1200 rads; therefore, permanent 50\% suppression occurs at a dose greater than 1200 rads. Table III sumarlzes the temporary and long-term $50 \%$ suppression doses observed in both the electron and proton experiments and the corresponding RBE's calculated from these ralues.

TABLE III

50\% FOLLICLE SUPPRESSIOW

TIme (Post

Dose (Rads)

R.B.H.

Irradiation)

-

Protons Electrons

10 Days

700

2100

3.00

24. Days

$>1200$

27000

$<2.25$ 
A fractionation effect for electrons was evident for both temporary and long-term follicle suppression. A fractionation effect was also observed for temporary suppression caused by protons. These results are sumarized in Table II. The amount of recovery from the first fraction can be estimated from the shift in the exponentially declining portion of the curve by means of the $\left(D_{2}-D_{1}\right)$ analysis described earlier. From Figure 8 the value of $D_{2}-D_{1}$ is 90 rads which corresponds to $60 \%$ recovery for protons. It should be noted that this estimate is made on the basis of temporary suppression (day 10). The long-term data for electrons in Figure 10 shows complete recovery $(100 ; 5)$ in the 2400 and 3600 rad dose groups. This estimate is somewhat higher. than the $80 \%$ recovery observed by Burns, et al ${ }^{10}$, however in that case the recovery was with respect to follicle survival at 80 weeks as compared to four weeks in this experiment.

The values of RBE calculated above indicate that protons are more effective in damaging hair follicle stem cells than electrons, suggesting a high linear energy transfer (IET) for the proton. According to Fowler's theory ${ }^{13}$ of LET dependence, a low IET particle (electron) exhibits substantial recovery and a high 
LET particle (proton) should exhibit littlo or no recovery. The recovery date presented here, $100 \%$ for elections and $60 \%$ for protons, indicates that protons sometimes behave more like low LET particles than high. Thus the proton possesses the characteristics of low LET particles (60\% recovery) and of high IET particles (RBE 2.25 - 3.00) simultaneously. The size of the stem cell population could not be estimated from the proton data because the hair a. follicle response indicated recovery which is to be expected from low rather than high LET. The extrapolation numbers obtained from the electron data were very large and varied from $10^{2}-10^{3}$ for temporary suppression to $10^{4}$ for long-term suppression.

There is some question as to whether permanent hair and follicle growth suppression is dependent solely on inactivation of the stem cell population, and therefore whether the use of the extrapolation number as an estimate of the population size is fustified. The possibility of damage to supporting tissue must also be considered. At high doses the skin in the irradiated area becomes completely ulcerated and thereby incapable of supporting hair growth. This could be the cause of temporary suppression 
rather than damage to the epidermal elements of the follicle as suggested by Geary?.

The shape of the regrowth curves in Figure 5 suggests that the hair development process has not slowed down but that its initiation has been delayed.

A comparison of the control growth curve with that of the 750 rad dose group shows that the shapes. of the individual curves are similar except that the 750 rad curve is delayed by seven days. . If the entire elongation process had slowed down, the initial slope of the 750 rad curve would be less than that of the control group. The fact that the initial (increasing) slopes of the growth curves in the 750 and 1250 rad dose groups are similar to the control group indicates that the follicles are still synchronized with respect to growth, in spite of the observed delay. The question of whether the delay is caused by the proliferation of the stem cell population or by supporting tissue damage cannot be ascertained on the basis of the data presented.

A distinction has been made between follicle elongation and actual hair growth. The inhibition of these two processes must be considered separatelJ because of the implications inherent in each effect. 
Inhibition of follicle elongation indicates that the ability of the stem cell population to proliferate has been limited. Whereas inhibition of hair growth indicates only that the ability of the follicle to produce hair has decreased; the existence or absence of cellular proliferation cannot be inferred from this data. 


\section{SOMMARY}

Temporary hair growth suppression and follicle elongation suppression has been observed in Albino rats following proton 1rradiation. Both temporary and long-term (24 days) follicle suppression were observed following electron irradiation. The delay in regrowth of new hair was about one day of delay per 100 rads of protons. Permanent total suppression occurred at 4800 rads for electrons and at a dose greater than 1200 rads for protons. The doses required to produce 50\% follicle suppression at ten days post irradiation were 700 rads and 2100 rads for protons and electrons, respectively. The RBE betreen protons and electrons calculated from these values was $<2.25$ for long-term suppression and 3.00 for temporary suppression. A fractionation effect was observed for both types of radiation with 60\% recovery for protons and $200 \%$ recovery for electrons. A parallel experiment is under way to study the effectiveness of single and fractionated doses of protons and electrons with respect to tumor induction in rat skin. 


\section{RELERENCES}

1) R E Albert, F J Burns, R D Heimbach. The Association between Chronic Radiation Damage of the Hair Follicles and Tumor Formation in the Rat. Radiation Research 30, pp. 590-599 (1967).

2) $F \mathrm{~J}$ Burns, $R E$ Albert, $R D$ Heimbach. The RBE for Skin Tumors and Hair Follicle Damage in the Rat following Irradiation with Alpha Particles and Electrons. Radiation Research 36, pp. 225241 (1968).

3) R D Heimbach, F J Burns, R E Albert. An evaluation by Alpha-Particle Bragg Peak Radiation of the Critical Depth in the Rat Skin for Tumor Induction. Radiation Research 39, pp.332344 (1969).

4) R D Malkinson and M L Griem. Biology of Skin and Hair Growth, (Lynne and Short, editors). Sydney: Angus and Robertson p.755.

5) R.F Oliver. The Dermal Papilla and the Development and Growth of Hair. J. Soc. Cosmet, Chem. 22 pp.741-755 (1971).

6) E O Butcher. The Hair cycles in the Albino Rat. Anatomical Records 61, pp.5-19 (1934). 
7) J R Geary. Effects of Roentgen Rays during Various Phases of the Hair Cycle of the AIbino Rat. Am. J. Anat. 9I, pp.51-105 (1952).

8). T E Burlin, I A Magnus, I Szur. The Effect of $X$-Rays on the Regrowth of Hair in the Mouse and Their Modification by Cysteamine. Radiation Research 34, pp.287-299.

9.) T E Burlin, A V J Challoner, I A Magnus, I Szur. The Effect of Divided Doses of X-Rays on the Regrowth of Hair in the Mouse. Int. J. Rad. Biol. 23, \#2 pp.121-131 (1973).

10) F J Burns, R E Albert, I P Sinclair, P Bennett. The Effect of Fractionation on Tumor Induction and Hair Follicle Damage in Rat Skin. Radiation Research 53, pp.235-24.0 (1973).

11). $\mathrm{R}$ Withers. Recovery and Repopulation in virn by Mouse Skin Epithelial Cells During Fractionated Irradiation. Radiation Research 32, pp.227-239 (1967).

12) M E Elkind, $\bar{i}$ Sutton. Radiation Response of Mammalian Cells grown in Culture. 1. Repair of X-Ray Damage in Surviving Chinese Hamster Cells. Radiation Research 13, pp.556-593 (1960). 
13) J F Fowler. Kinetics of Injury and Repalr to Mammalian Tissue by High LET Radiation. Radiation Research Suppl. ?, pp.276-287 (1967)

14) A P Casaret. Radiation BiologI, Prentice-Hall, Englewood Cliffs, New York (1968).

15) A Birge, H D Anger, C A Tobbias. Heavy Charged Particle Beams. In: Radiation Dosimetry. G J Hine and G I Brownell, Academic Press (1956).

16) D E Lea. Actions of Radiations on Living Cells. Cambridge University Press (1955).

17) D. V Huntsberger, P E Leaverton. Statistical Inference in the Biomedical Sciences, Allyn \& Bacon, Inc. Boston (1970).

18) W.J Dixon, F J Massey, Jr. Introduction to Statistical Analysis, McGraw-Hill, New York, (1969). 


\section{FIGURES}

Figure 1 Depth-dose profile of proton beam in tissue.

Figure 2 Depth-dose profile of electron beam in tissue.

Figure 3 Ifinear plot of time to reach 50\% normal hair density following irradiation versus surface dose of protons.

Figure 4 Total number of hairs per unit area of rat skin versus time after, irradiation with protons.

Figure 5. Number of new hairs per unit area of rat skin versus time after irradiation with protons.

Figure 6 Total hair growth at ten days post Irradiation versus surface dose of protons.

Figure 7 Number of growing stage follicles per unit area of rat skin at ten days post Irradiation versus surface dose of protons.

Figure 8 Semi-logarithmic plot of growing stage follicle survival at ten days post irradiation versus surface dose of protons.

Figure 9 Number of growing stage follicles per unit area of rat skin at ten days post irradiation versus surface dose of electrons. 
Figure 10

Figure II

:

\section{Figure. 13}

Figure 12

\section{- protons.}

Figure $I_{4}$ Diagram of proton irradiation system. 


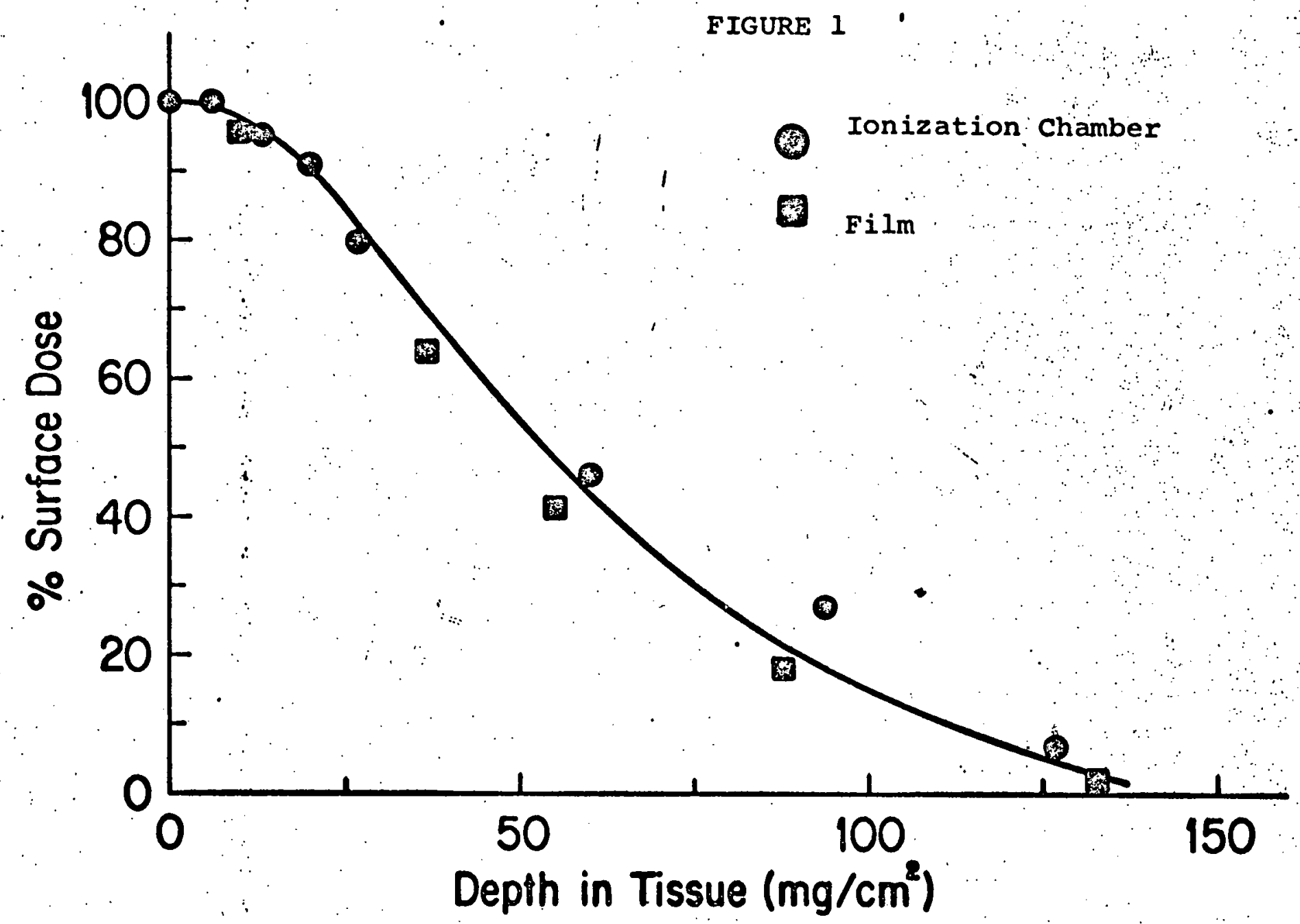




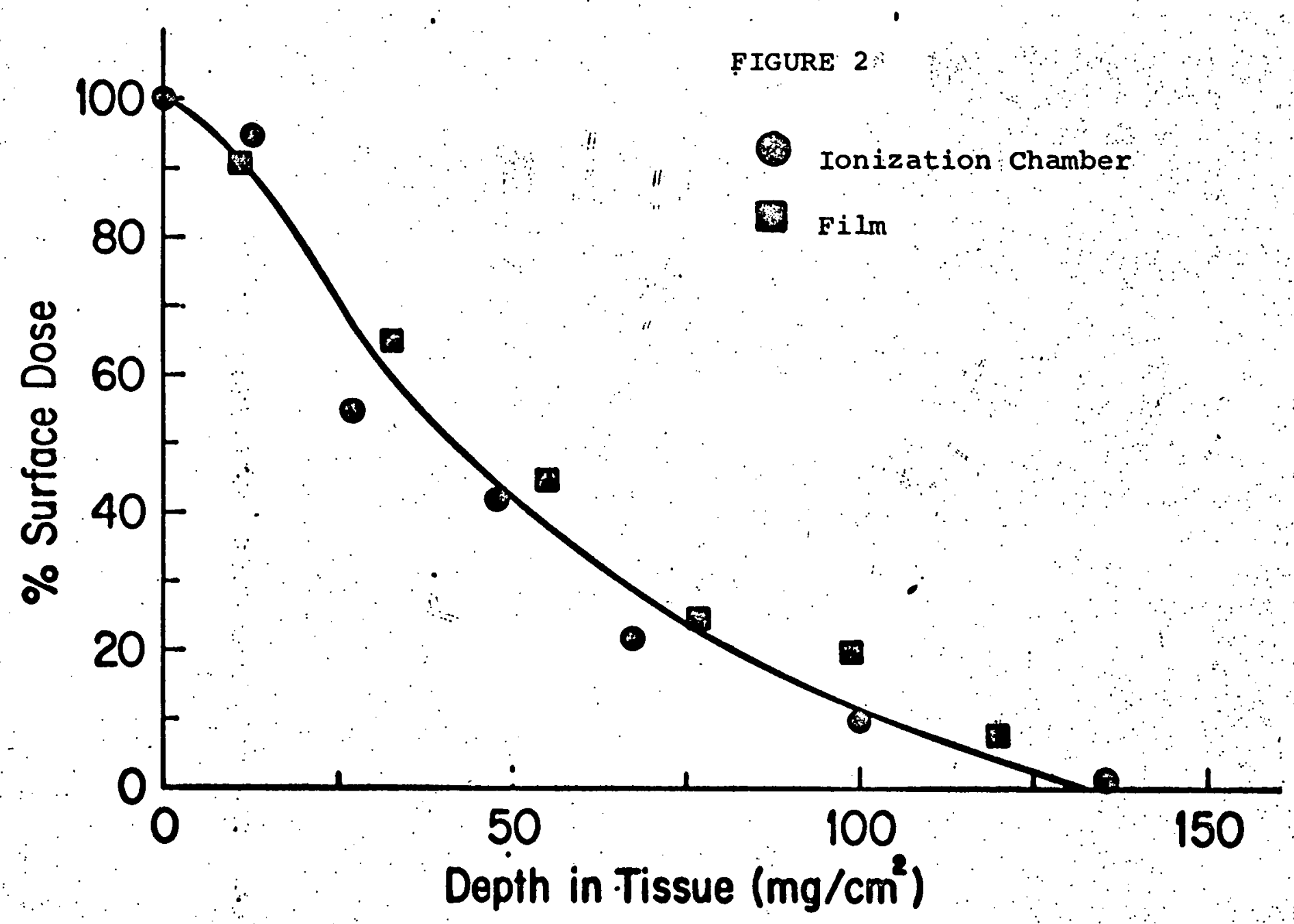




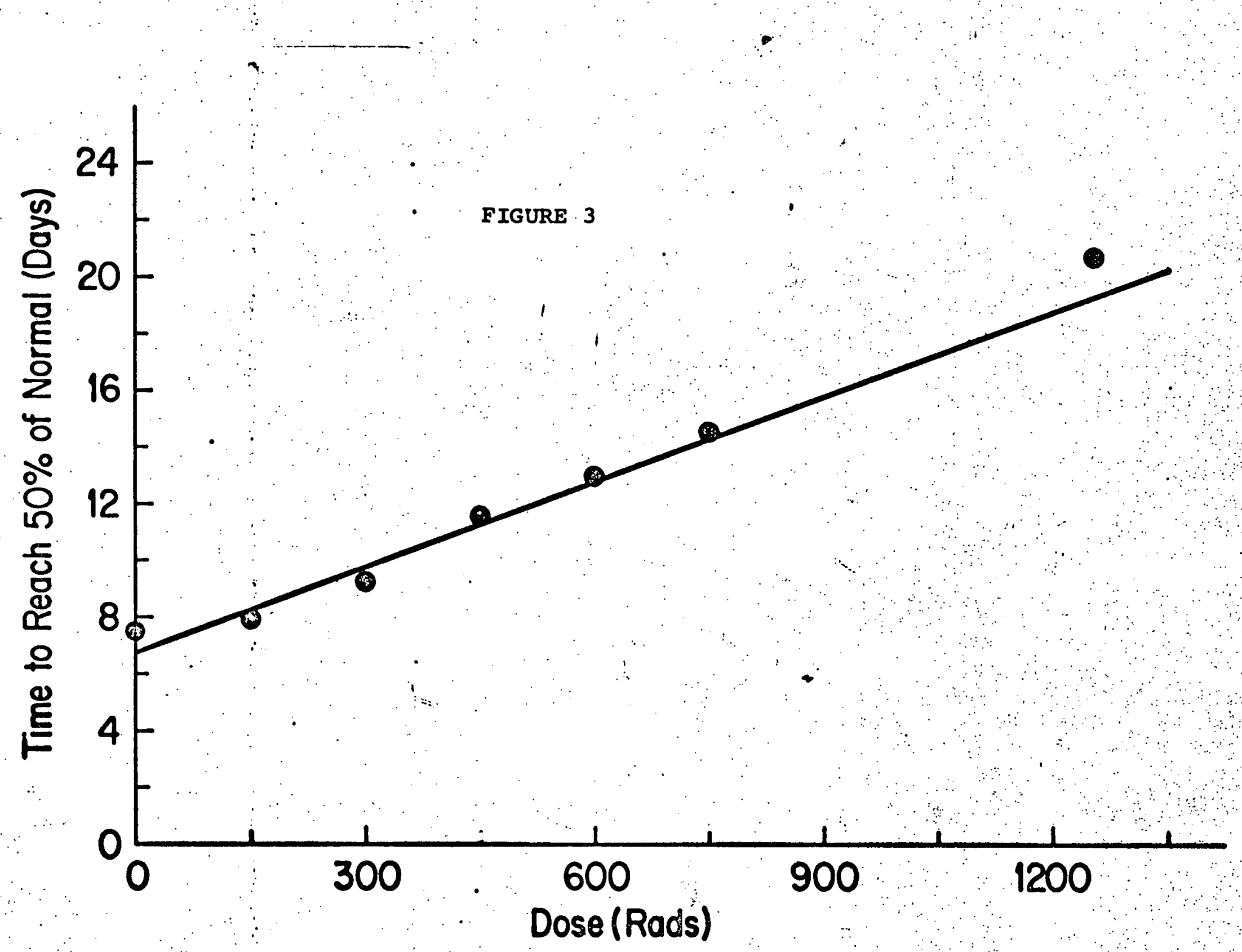




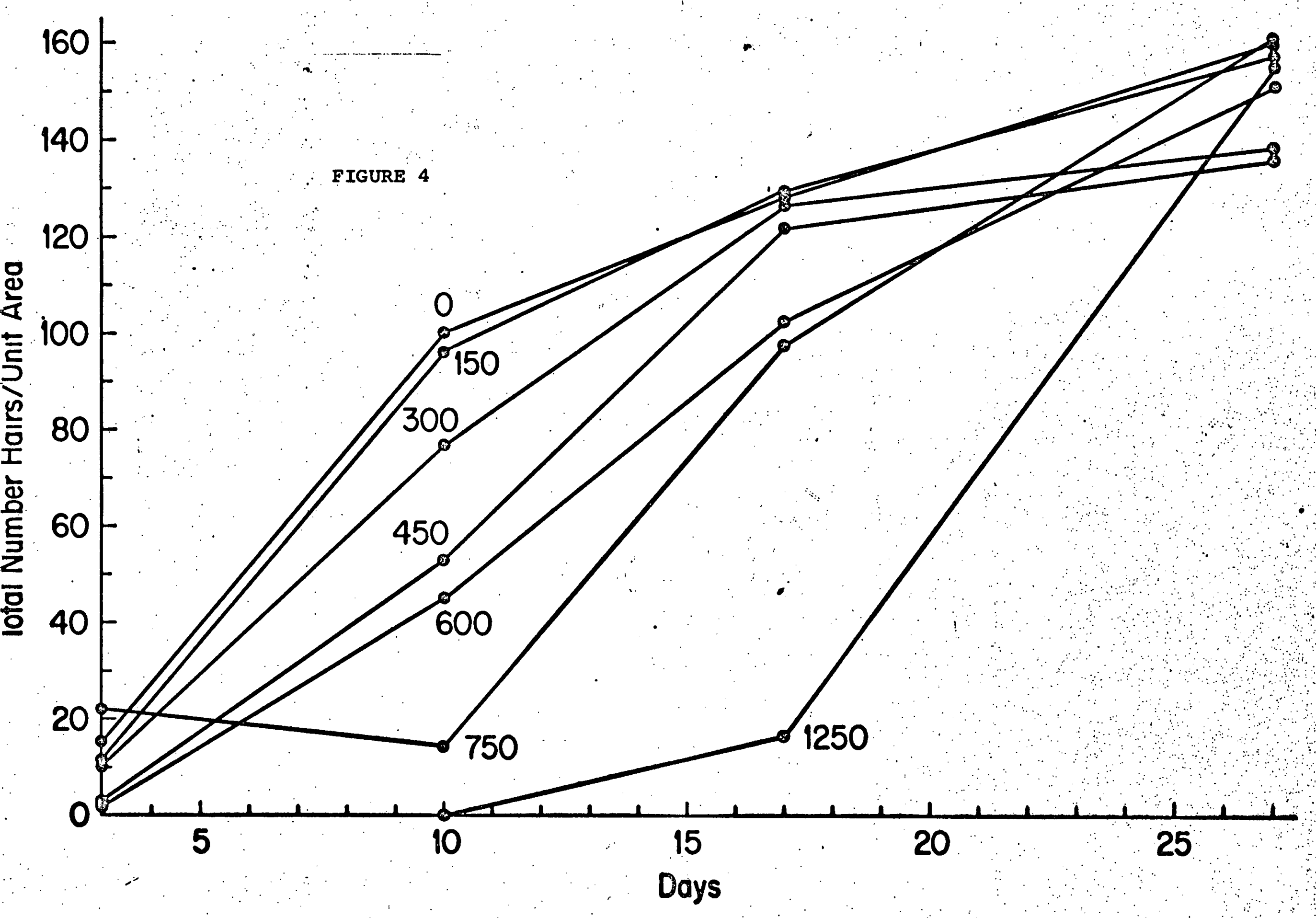




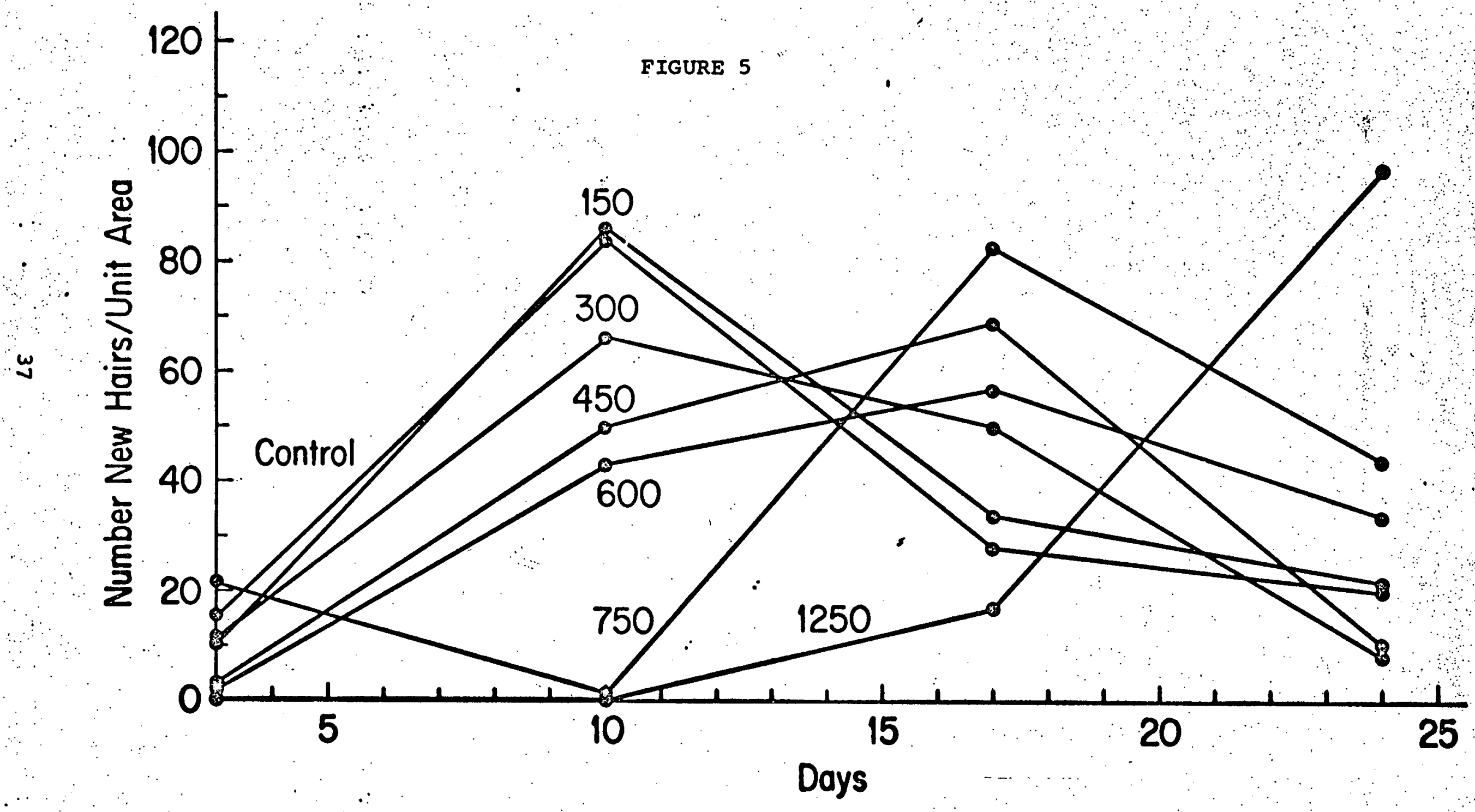




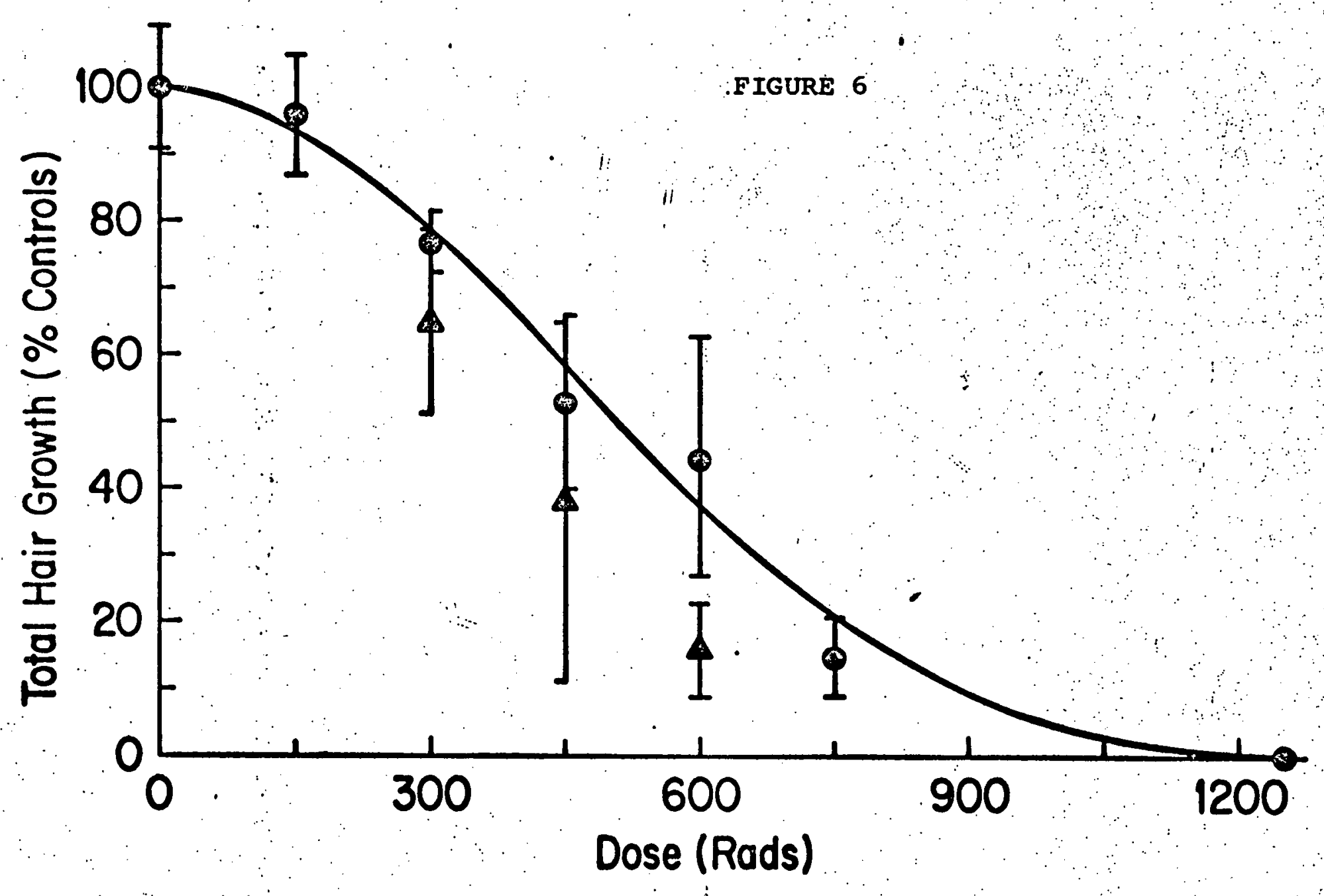




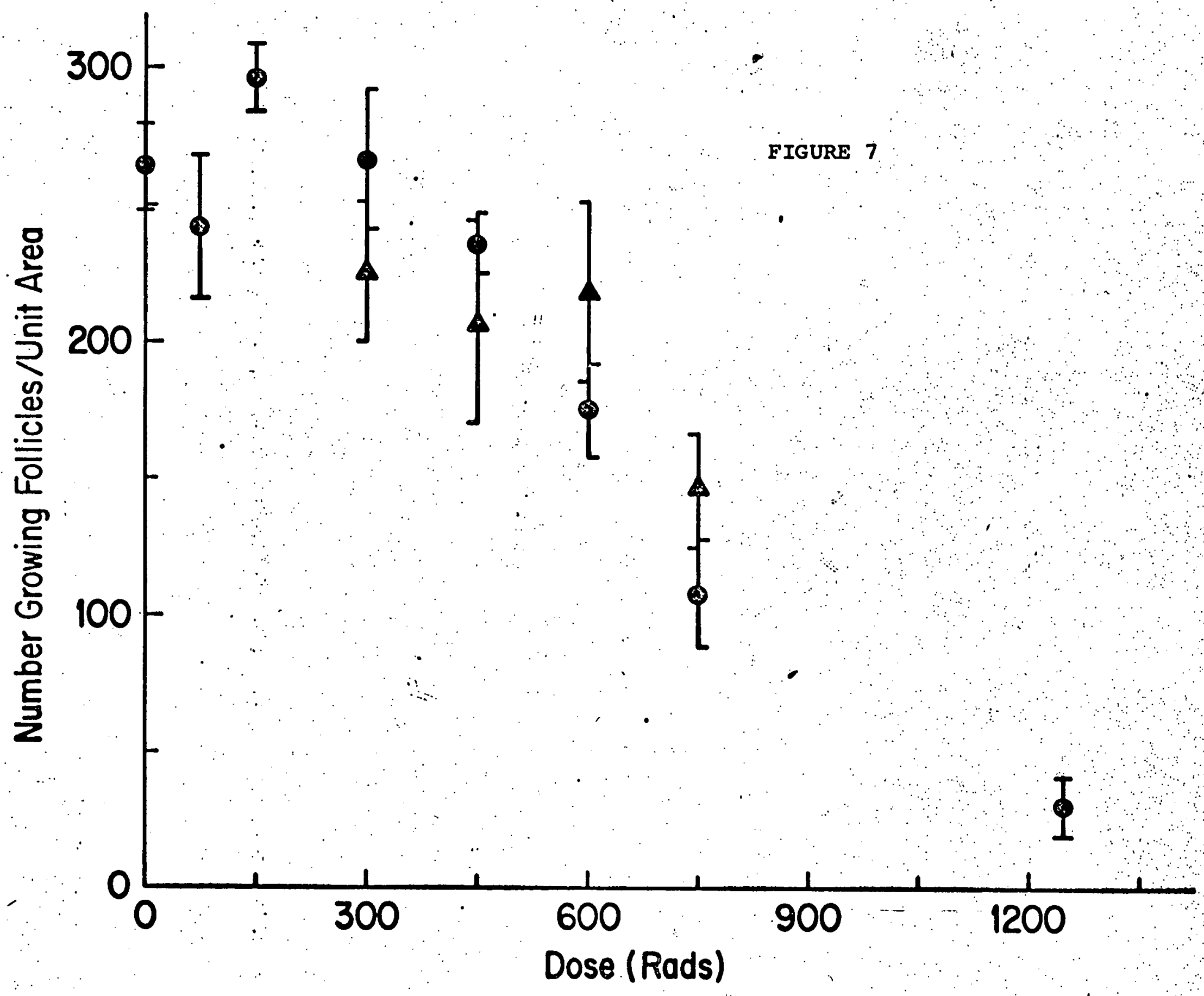




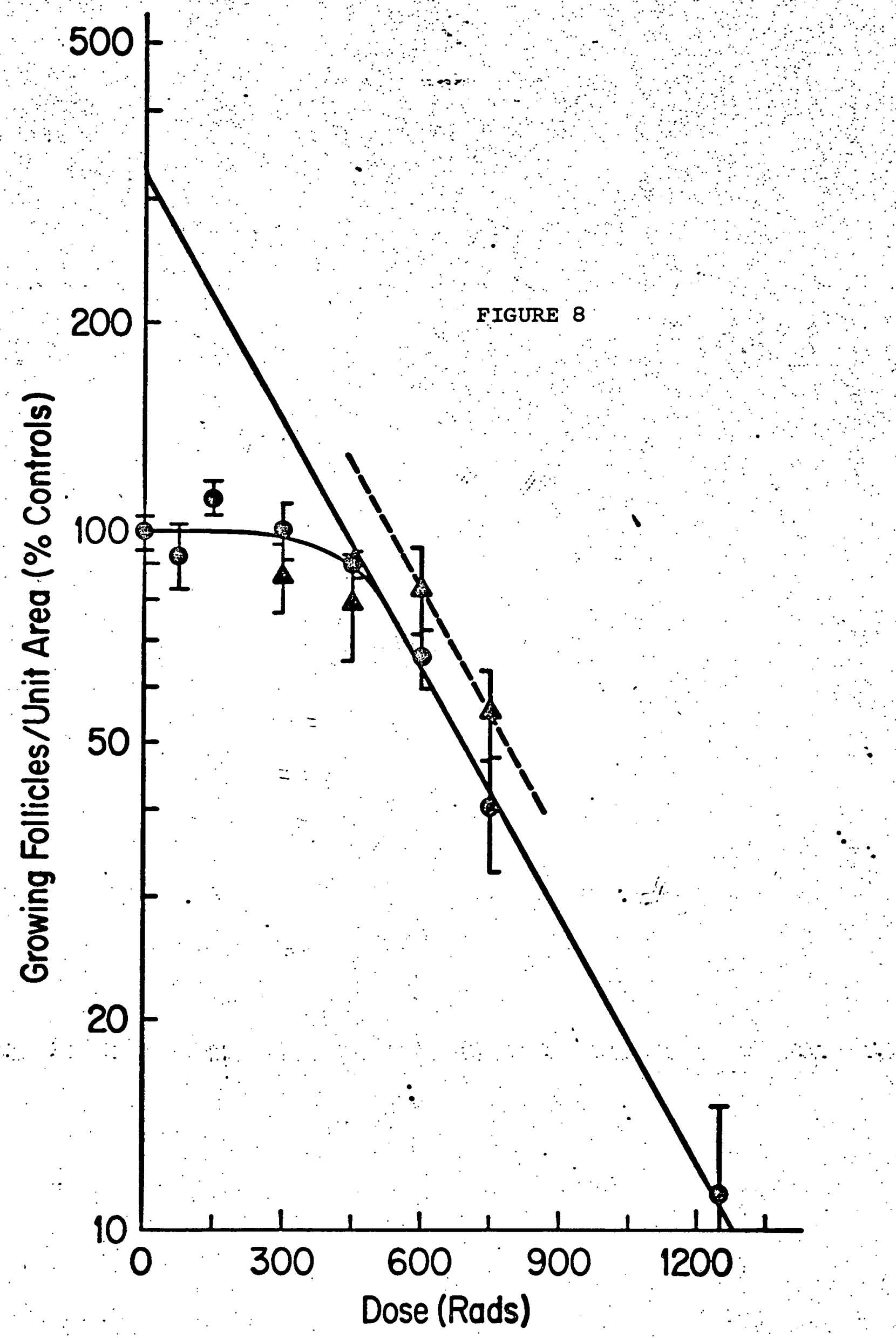




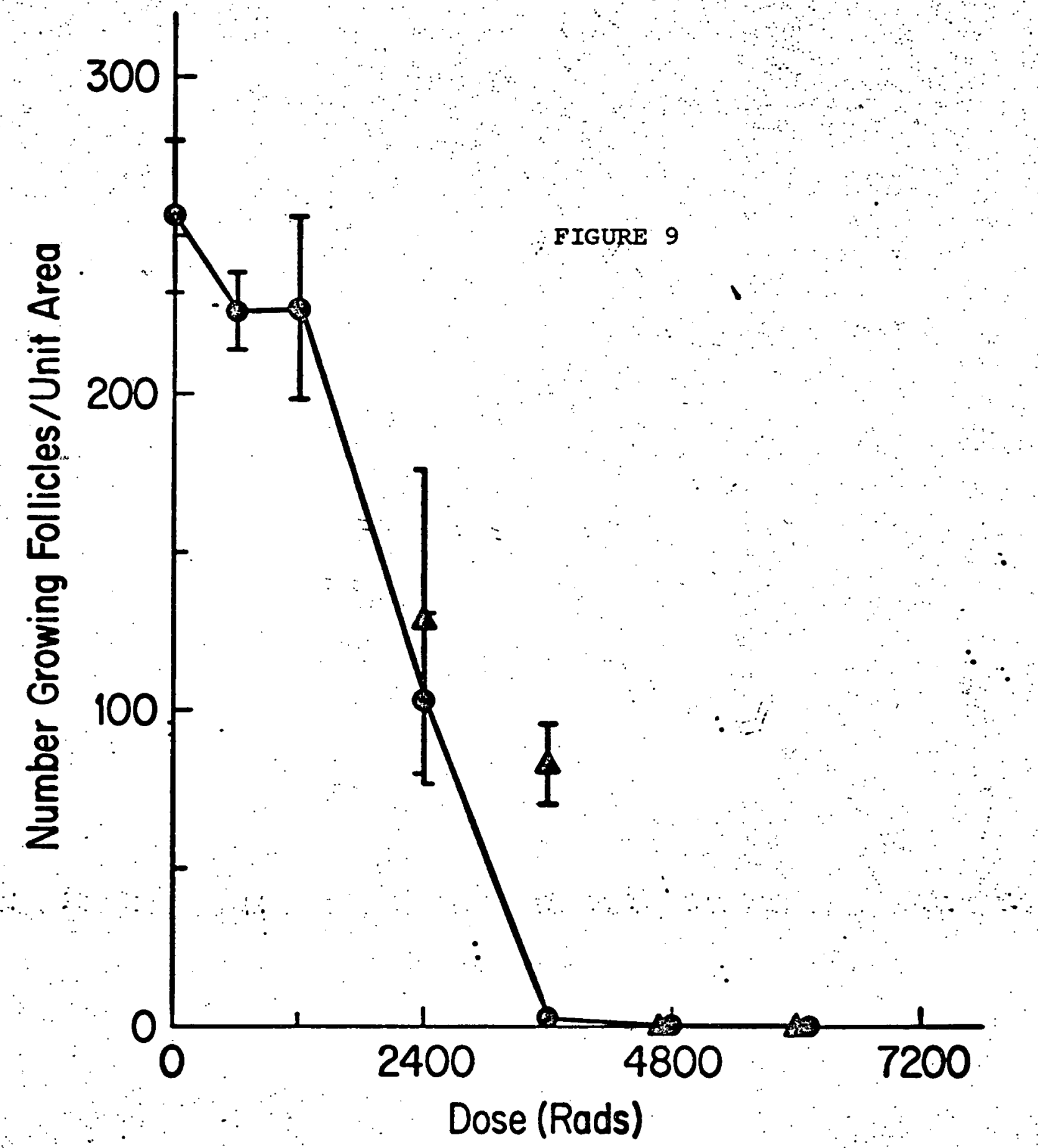




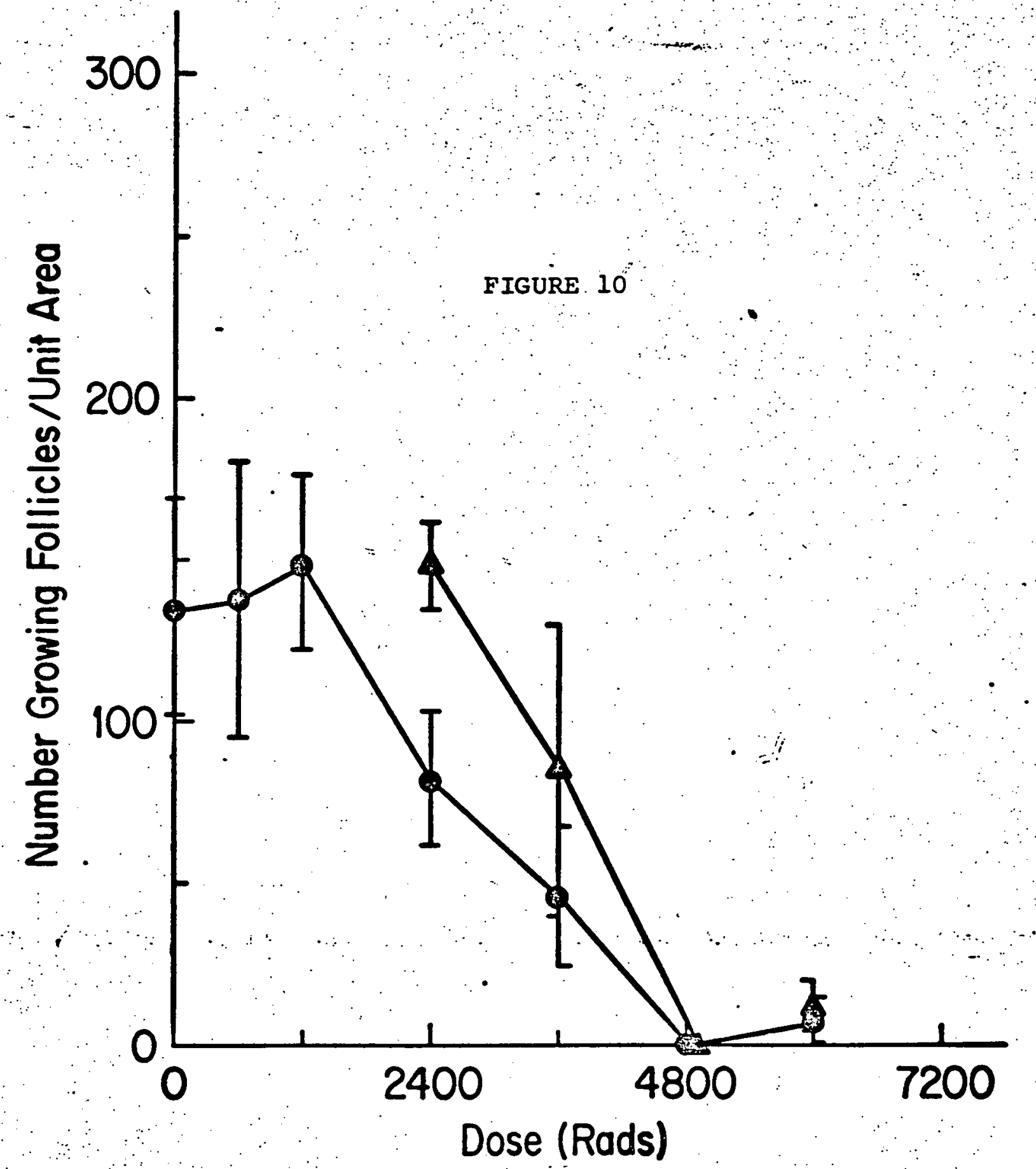




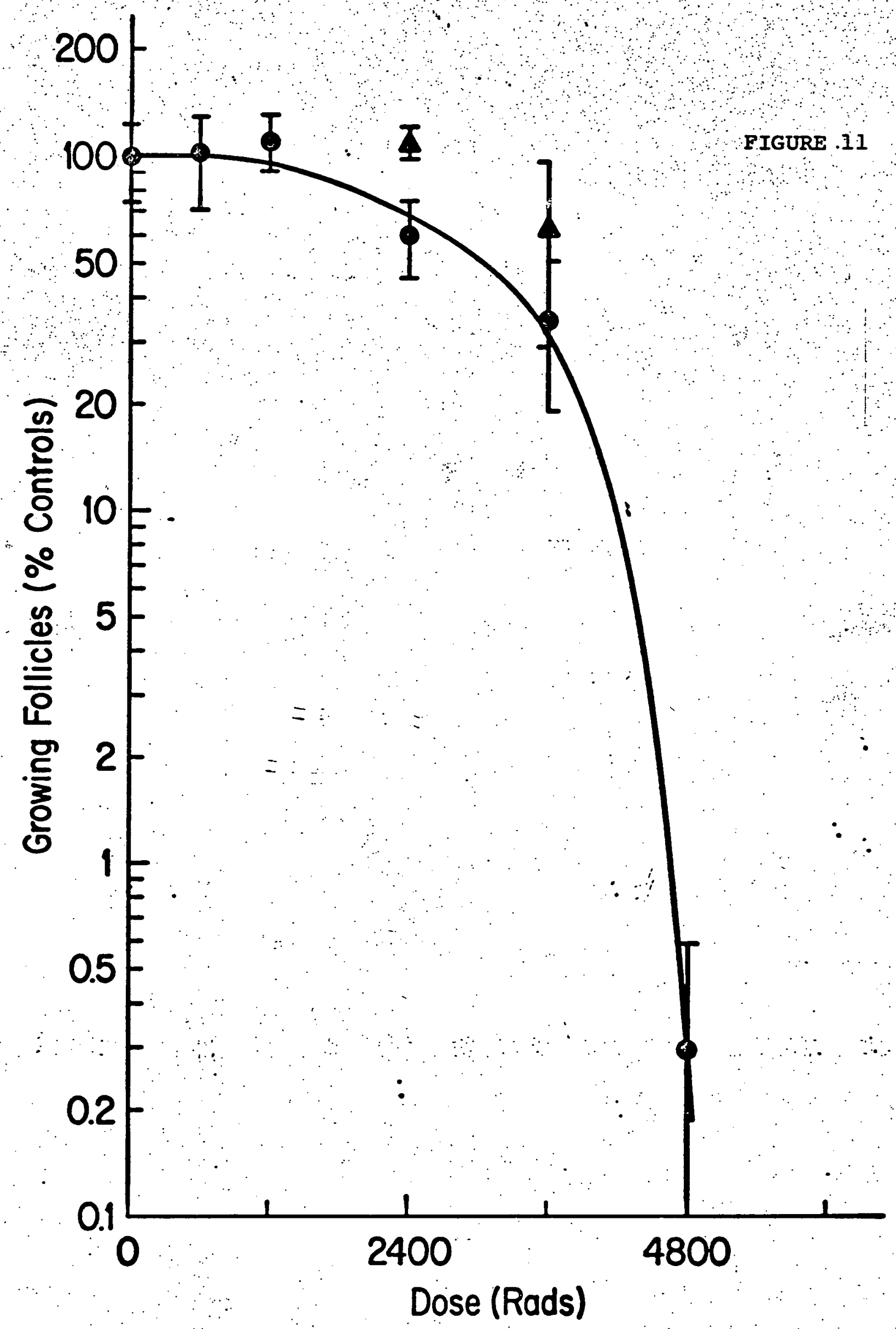




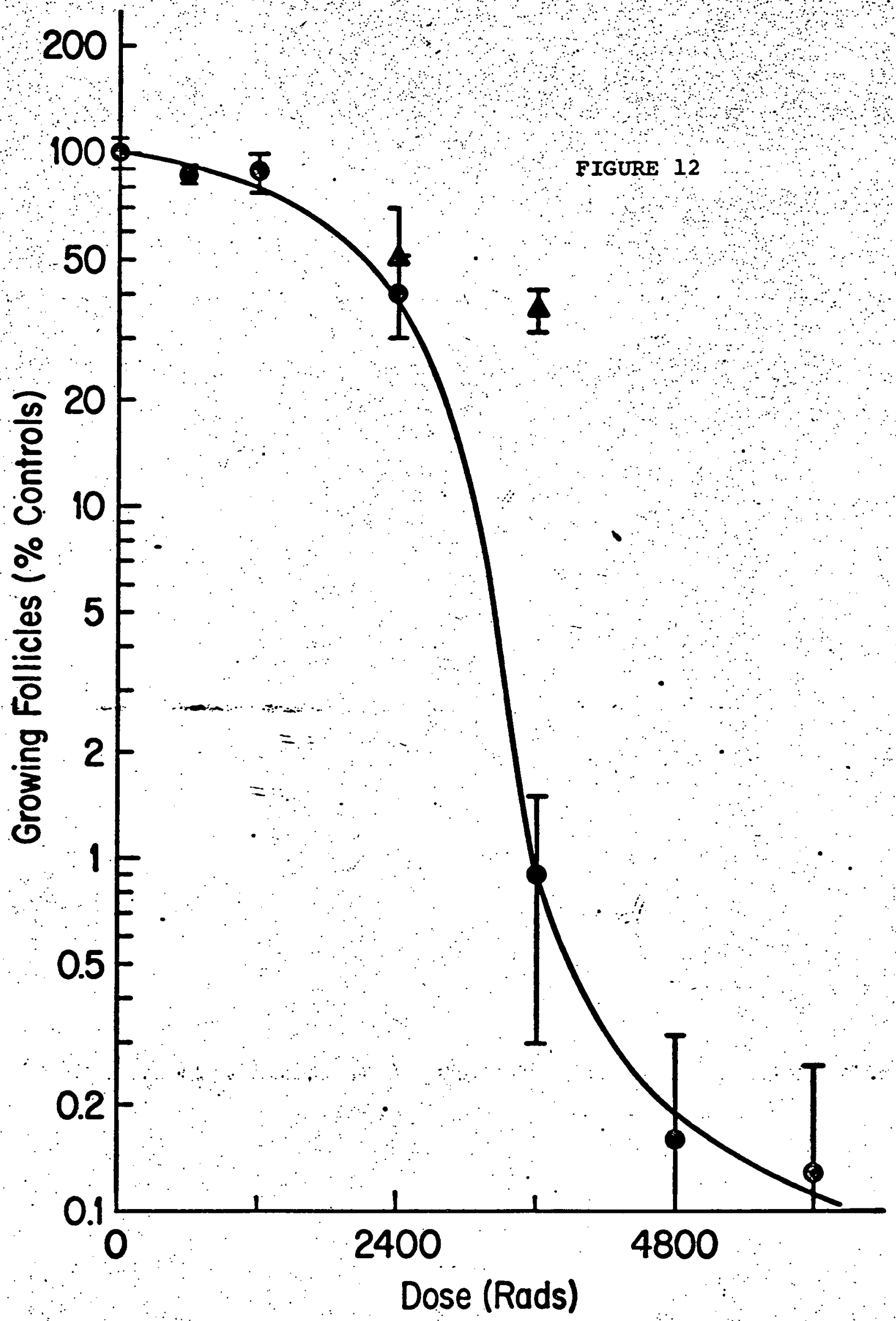


FIGURE 13

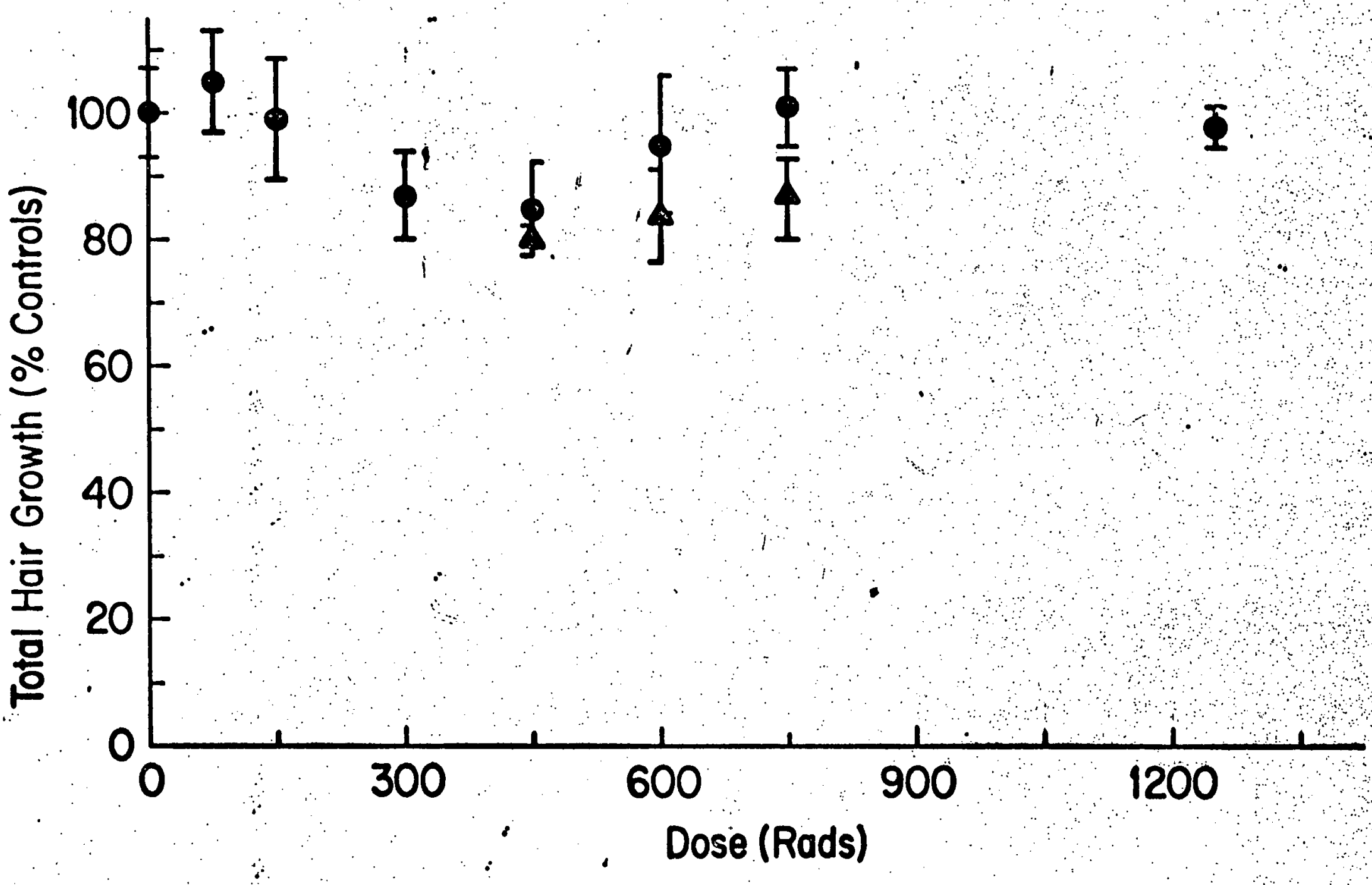




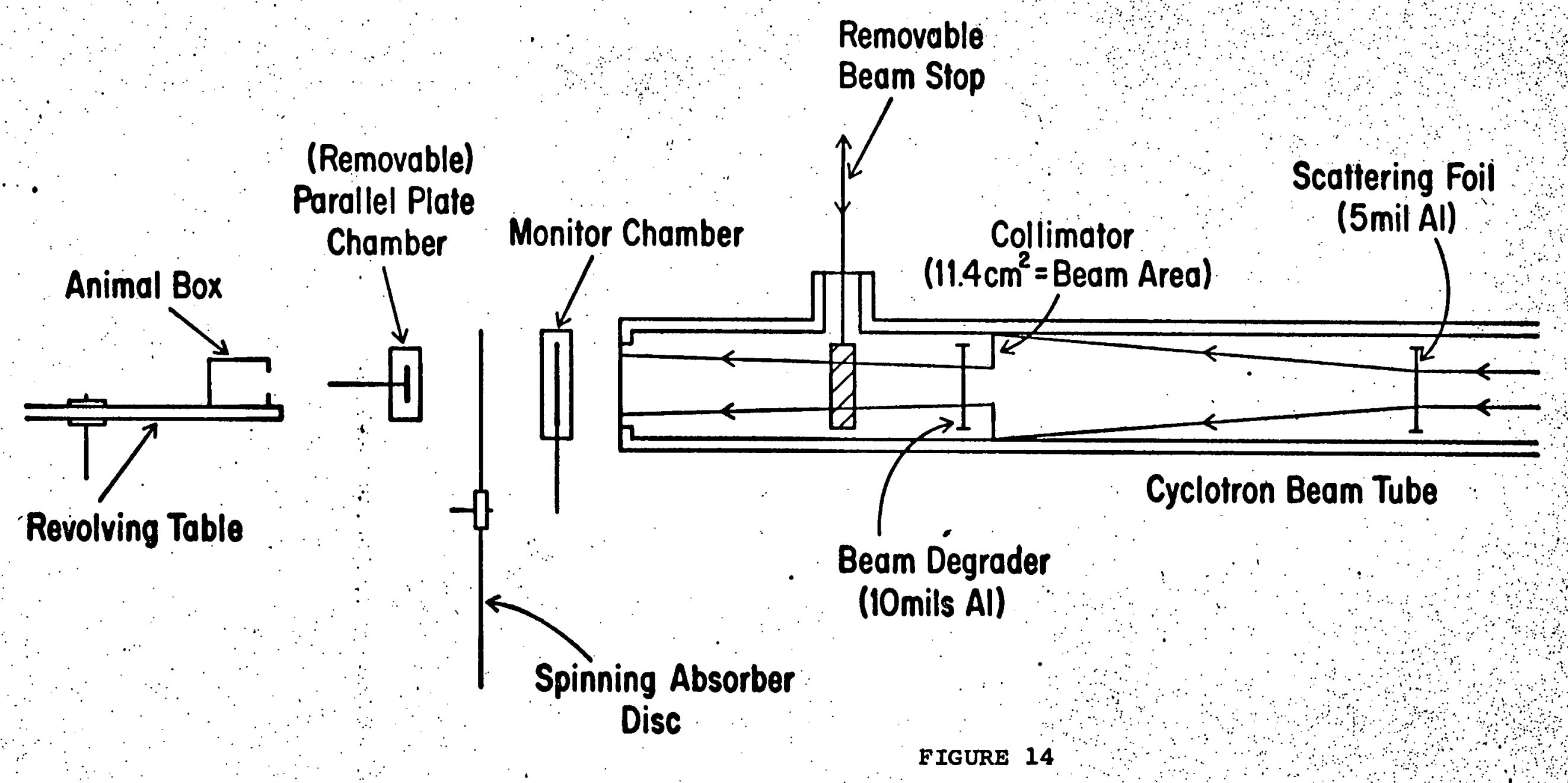




\section{APPEAIDIX I}

\section{ELECTRON DOSTMETRY}

The Bragg-Gray principle can be used as a means of relating the dose rate at a small air cavity, in an irradiated medium, to the characteristics of the carity and air. The relationship is as follows: 15

$$
\text { Dose Rate }=\frac{d D}{d t}=\frac{I W p}{v d} 10^{5} \frac{\text { rads }}{\text { sec }}
$$

where: - I = saturation current (amps)'

$$
\begin{aligned}
w= & \text { energy expended per ion pair }(34 \mathrm{eV} / \text { ion pair }) \\
\nabla= & \text { volume of collecting cavity }\left(.143 \mathrm{~cm}^{2}\right) \\
d= & \text { density of air }\left(1.29 \times 10^{-3} \mathrm{gm} / \mathrm{cm}^{3}\right) \\
p= & \text { reletive mass stopping power of tissue } \\
& \text { to air (1.135) }
\end{aligned}
$$

Upon substituting the appropriate values we obtain for the dose rate:

$$
\begin{aligned}
\frac{d D}{d t} & =2.08 \times 10^{10} \mathrm{I} \text { (amps) } \mathrm{rad} / \mathrm{sec} \\
& =1.26 \times 10^{12} \mathrm{I} \text { (amps) } \mathrm{rad} / \mathrm{min}
\end{aligned}
$$

The chamber current used in the experiment was $3.65 \times 10^{-10} \pm 10 \%$ amps; corresponding to a dose rate of:

$$
\frac{\mathrm{dD}}{\mathrm{dt}}=1.26 \times 10^{12}\left(3.65 \times 10^{-10}\right)=460 \pm 46 \mathrm{rad} / \mathrm{mln}
$$

Thus a surface dose rate of 460 rads was used with exposure times calculated accordinglJ. 


\section{APPENDIX II}

\section{PROTON DOSTMETRY}

In order to calculate the proton beam dose, the beam flux was measured and converted to dose rate. The beam flux was monitored continuousig during the experiment by means of an argon filled double ionization chamber with 205 volts applied to the central foil. The chamber current was integrated to compensate for beam fluctuations (which were small).

The monitor chamber was calibrated by means of a removable beam stop (faraday cup) in the beam tube of the cyclotron (see figure 15). The ratio of the beam stop current to the monitor chamber current was found to be $4.2 \times 10^{-4}$ up to a beam current of 1.0 nanoamp. The beam was operated at 0.4 nanoamps, or a monitor chamber reading of 0.95 uamps. The dose rate to the animals was calculated as follows :

$$
\begin{array}{rl}
\text { Beam current }=I_{b} & =\left(0.95 \times 10^{-6}\right) 4.2 \times 10^{-4} \\
I_{b}=F q A & 0.4 \text { nanoamp }
\end{array}
$$

where: $F=$ beam flux (protons $/ \mathrm{cm}^{2}$ sec)

$q=$ proton charge $\left(1.6 \times 10^{-19}\right.$ coulomb/proton $)$

$A$ = area of beam $\left(11.4 \mathrm{~cm}^{2}\right)$ 
Solving for the flux; we obtain:

$$
\begin{aligned}
& F=I_{b} / q A \\
& F=\frac{4.0 \times 10^{-10}}{11.4\left(1 / 6 \times 10^{-19}\right)} \text { protons } / \mathrm{cm}^{2} \text { sec } \\
& F=2.2 \times 10^{8} \text { protons } / \mathrm{cm}^{2} \text { sec }
\end{aligned}
$$

We can now use the relation:

$$
\frac{d D}{d t}=F \frac{d E}{d R}
$$

to calculate the dose rate from the flux and the average energy loss per unit distance. The energy of the protons was $10 \mathrm{MeV}$ for which the range in tissue is $1.2 \mathrm{~mm}^{16}$ or $0.12 \mathrm{gm} / \mathrm{cm}^{2}$. The average value

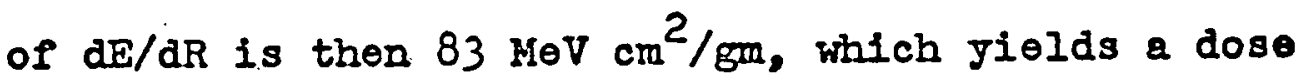
rate of:

$$
\frac{d D}{d t}=2.2 \times 10^{8}(83)=1.83 \times 10^{10} \mathrm{MeV} / \mathrm{gm} 8 \theta 0
$$

when substituted into the previous equation. Converting to orgs and then rads, we cave:

$$
\begin{aligned}
\frac{d D}{d t} & =2.93 \times 10^{4} \mathrm{erg} / \mathrm{gm} \text { sec } \\
& =2.93 \times 10^{2} \mathrm{rad} / \mathrm{sec} \\
& =1.76 \times 10^{4} \mathrm{rad} / \mathrm{min} .
\end{aligned}
$$

By using the table rotation factor $(1 / 115=.0087)$

and the rib reduction factor of the spinning disc (.90), wo obtain a final dose rate to the arimals of:

$$
\frac{d D}{d t}=138 \mathrm{rad} / \mathrm{min}
$$


It was later found that during the original monitor chamber calibration, the Keithley electrometer used to measure the faraday cup current was in error by a factor of two. As a result, the observed dose rate of $138 \mathrm{rad} / \mathrm{min}$ was actually $50 \%$ of the intended dose rate. Fiowever this error was subsequently found and the final doses to the animals were corrected. The dose rate was checked with the parallel plate chamber described earlier in the electron section. - This chamber yielded a dose rate of $162 \mathrm{rad} / \mathrm{min}$ which is about $17 \%$ higher than the monitor chamber reading. The corrected monitor chamber reading was considered to be more accurate and was used in the experiment. 


\section{APPENDIX III}

\section{BIOPSY STAINING PROCEDURE}

The staining and clearing procedures used to prepare the biopsies for counting are listed below: Staining:

1) Carnoy solution - 2 to 3 hours

2) $70 \%$ alcohol (can store up to one month)

3) $\mathrm{H}_{2} \mathrm{O}$ - ten minutes

- 4) $\operatorname{LiCl}\left(60^{\circ}\right)-5$ minutes

5) $\mathrm{H}_{2} \mathrm{O}-5$ minutes

6) Remove muscle layer

7) Schiff's solution - 5 minutes

8) $\mathrm{NaHCO}_{3}-5$ minutes

9) Acetic acid (45\%) - 10 minutes

10) 70\% alcohol - sereral days (change once)

Clearing:

1) $95 \%$ alcohol - 2 hours

2) $100 \%$ alcohol - 4 hours (change once)

3) Xylene - 2 hours

4) methyl salicylate - 2 hours (storage)

After the biopsies were counted, they were mounted on slides for storage. 